\title{
PROPRIEDADES FÍSICAS DE SOLO E CRESCIMENTO DE BATATA-DOCE EM DIFERENTES SISTEMAS DE PREPARO ${ }^{(1)}$
}

\author{
Amarílis Beraldo Rós ${ }^{(2)}$, João Tavares Filho ${ }^{(3)}$ \& Graziela Moraes de Cesare Barbosa ${ }^{(4)}$
}

\begin{abstract}
RESUMO
Trabalhos sobre preparo reduzido em solos cultivados com raízes e tubérculos são escassos e controversos. Assim, este trabalho teve por objetivo avaliar o impacto de sistemas de preparo em propriedades físicas de um Argissolo Vermelho-Amarelo e no crescimento de raízes tuberosas de batata-doce. Para avaliação das propriedades físicas do solo, foi instalado experimento em blocos ao acaso, esquema de parcelas subdivididas. As parcelas corresponderam aos tratamentos: preparo convencional, com confecção de leiras, e preparo reduzido, com manutenção de palhada superficial e as subparcelas, às épocas de coleta: 120 e 180 dias após o plantio (DAP) da cultura de batata-doce. Foram avaliados os atributos físicos densidade do solo, porosidade total, macro e microporosidade, resistência do solo à penetração e umidade gravimétrica do solo. Para avaliação do crescimento de raízes tuberosas de batata-doce, montou-se experimento em que as parcelas corresponderam às formas de manejo do solo, e as subparcelas às quatro épocas de colheita: 90, 120, 150 e 180 DAP. Avaliaram-se as relações comprimento/diâmetro e massa fresca individual/comprimento de raízes tuberosas. $O$ preparo convencional do solo com confecção de leiras, em oposição ao preparo reduzido, promoveu menores valores de densidade do solo, resistência do solo à penetração e microporosidade, maiores valores de porosidade total e macroporosidade; proporcionou menor manutenção de água na camada superior do solo $(0-0,15 \mathrm{~m})$; e permitiu maior crescimento vertical de raízes tuberosas de plantas de batatadoce.
\end{abstract}

Termos de indexação: Ipomoea batatas, plantio direto, densidade do solo, resistência do solo à penetração, porosidade do solo, formato de raiz.

(1) Parte da Tese de Doutorado da primeira autora. Recebido para publicação em 26 de abril de 2012 e aprovado em 11 de dezembro de 2012.

(2) Pesquisadora Científica III da Agência Paulista de Tecnologia dos Agronegócios - APTA, Pólo Alta Sorocabana. Rodovia Raposo Tavares, km 561, Caixa Postal 298. CEP 19015-970 Presidente Prudente (SP). E-mail: amarilis@apta.sp.gov.br

(3) Professor Associado C do Departamento de Agronomia da Universidade Estadual de Londrina - UEL. Rodovia Celso Garcia Cid km 380, Caixa Postal 6001. CEP 86051-980 Londrina (PR). E-mail: tavares@uel.br

(4) Pesquisadora do Instituto Agronômico do Parará - IAPAR. Rodovia Celso Garcia Cid, km 375. CEP 86047-902 Londrina (PR). E-mail: graziela_barbosa@iapar.br 


\title{
SUMMARY: SOIL PHYSICAL PROPERTIES AND GROWTH OF SWEET POTATO UNDER DIFFERENT SOIL MANAGEMENTS
}

\begin{abstract}
Studies about reduced tillage in soil cultivated with roots and tubers are rare and controversial. Thus, this study assessed the impact of tillage systems on physical properties of an Alfissol and on the growth of sweet potato tubers. To evaluate the soil physical properties, an experiment was conducted in a randomized block, split-plot design. The plots consisted of the treatments conventional tillage with mounds and reduced tillage with straw on the soil surface and the subplots of two sampling periods: 120 and 180 days after planting (DAP) of sweet potato. The soil physical properties - soil bulk density, total soil porosity, soil macroporosity and microporosity, penetration resistance and gravimetric soil water content were evaluated. For the assessment of the growth of sweet potato tuberous roots, an experiment was carried out where the plots corresponded to the soil management forms and subplots to four sampling periods: 90, 120, 150, and 180 (DAP). The ratios root length/diameter and fresh mass / length were evaluated. Conventional tillage with mounds, opposite to reduced tillage (no-tillage), resulted in lower values of soil bulk density, penetration resistance and microporosity, higher scores of total porosity and macroporosity, lower water maintenance in the soil surface (0-0.15 $m$ ) and increased vertical growth of sweet potato tubers.
\end{abstract}

Index terms: Ipomoea batatas, no-tillage, soil bulk density, penetration resistance, soil porosity, root shape.

\section{INTRODUÇÃO}

A cultura da batata-doce é cultivada após intenso revolvimento do solo, promovido por meio do uso de arados e grades (Zero \& Lima, 2005), embora Barrera (1986), na década de 1980, já recomendasse o plantio de batata-doce em sulco em solos arenosos, visto que a construção de leiras contribui para a perda da umidade do solo, podendo-se formar os camalhões durante as operações de capina e amontoa.

Sabendo-se que, dentre os componentes do manejo, o preparo do solo é a atividade que mais influencia o comportamento físico do solo, por atuar diretamente na sua estrutura (Vieira \& Klein, 2007), o uso de práticas que promovam menor revolvimento do solo, como o plantio direto sobre palha, resulta em menor perda de solo por erosão hídrica, contribuindo ainda para a manutenção da umidade no solo. Entretanto, não há relatos de cultivo de batata-doce sob esse sistema no Brasil.

Quanto ao efeito dos sistemas de preparo de solo para a implantação da cultura da mandioca sobre as propriedades físicas do solo, em Argissolo Vermelho textura arenosa, Silva et al. (2008) relatam que, na fase inicial do estabelecimento da cultura, o plantio convencional resultou em menor densidade, maior macroporosidade e porosidade total do solo, em comparação ao plantio direto. De maneira semelhante, Tormena et al. (2002), comparando densidade, volume de macro e microporos, porosidade total e resistência do solo à penetração, em um Latossolo Vermelho distrófico, sob sistemas de preparo de solo convencional, mínimo e plantio direto, verificaram que o plantio direto proporcionou condições físicas menos favoráveis ao crescimento de plantas de mandioca, quando comparado aos outros dois sistemas. Contudo, Otsubo et al. (2008) concluíram ser viável a implantação da cultura da mandioca em área minimamente preparada em Argissolo Vermelho.

No cultivo de batata-inglesa, em solo de textura argilosa, Fontes et al. (2007) relataram menor produtividade de tubérculos em sistema de plantio direto, quando comparado ao uso de arado de aiveca seguido de grade niveladora. No entanto, Carter \& Sanderson (2001) consideraram o preparo reduzido do solo uma alternativa viável para a produção da cultura.

Este trabalho teve por objetivo avaliar o impacto de sistemas de preparo sobre propriedades físicas do solo e sobre o crescimento de raízes tuberosas de batata-doce.

\section{MATERIAL E MÉTODOS}

O trabalho foi conduzido na Agência Paulista de Tecnologias dos Agronegócios (APTA), Polo Alto Sorocabana, em Presidente Prudente (SP), de março de 2009 a abril de 2010. O solo foi classificado como Argissolo Vermelho-Amarelo (Embrapa, 2006). Foi realizada amostragem do solo sob preparo reduzido nas camadas de 0-0,15 e 0,15-0,30 m para determinação da granulometria, com os seguintes resultados: $920 \mathrm{e}$ $930 \mathrm{~g} \mathrm{~kg}^{-1}$ de areia; 30 e $20 \mathrm{~g} \mathrm{~kg}^{-1}$ de silte; 50 e $50 \mathrm{~g} \mathrm{~kg}^{-1} \mathrm{de}$ argila, respectivamente.

A área experimental era constituída por pastagem perene de Brachiaria decumbens há mais de cinco anos. A pastagem foi dessecada aplicando-se glifosato para a instalação de milho safrinha, cultura destinada à sistematização da área experimental. $\mathrm{O}$ milho foi semeado em plantio direto, densidade de 45.000 plantas $\mathrm{ha}^{-1}$, em março de 2009. Em outubro de 2009, as plantas secas de milho foram roçadas para a instalação 
dos tratamentos preparo convencional (PC) e preparo reduzido $(\mathrm{PR})$. A palha de milho associada à palha dessecada de plantas de braquiária que emergiram do banco de sementes existente no solo no final do ciclo da cultura do milho (13 tha $\left.{ }^{-1}\right)$ foi incorporada ao PC e mantida sobre a superfície do solo no PR. O PC foi realizado por meio de uma aração com grade de disco, a uma profundidade entre $0,25-0,30 \mathrm{~m}$, seguida de uma gradagem niveladora e posterior levantamento de leiras com sulcador, enquanto no PR houve movimentação do solo apenas nas linhas de plantio, constituídas por sulcos abertos com uso de enxada.

O delineamento experimental foi em blocos ao acaso, em esquema de parcelas subdivididas, com nove repetições. Para efeito de comparação entre solo de área cultivada e área com vegetação nativa, também foi avaliada área de mata nativa (Mata) sobre Argissolo Vermelho-Amarelo, a aproximadamente $300 \mathrm{~m}$ do experimento, utilizando-se o teste de comparação de médias de Dunnett a $5 \%$, visto que a área de mata não pode ser incluída na análise estatística como um tratamento, por não atender aos pressupostos do respectivo delineamento experimental. $\mathrm{Na}$ área de Mata, os dados da análise granulométrica foram: 797 e $823 \mathrm{~g} \mathrm{~kg}^{-1}$ de areia; 138 e $122 \mathrm{~g} \mathrm{~kg}^{-1}$ de silte; 65 e 55 $\mathrm{g} \mathrm{kg}^{-1}$ de argila, nas camadas $0-0,15$ e $0,15-0,30 \mathrm{~m}$, respectivamente.

Cada parcela experimental de $16,2 \mathrm{~m}^{2}$ apresentou três leiras por linhas distanciadas $0,9 \mathrm{~m}$, onde foram plantadas 20 ramas de $0,3 \mathrm{~m}$ cada, oriundas de ponteiros de plantas de batata-doce, espaçadas a cada $0,3 \mathrm{~m}$, o que correspondeu a 37.000 plantas ha ${ }^{-1}$. O plantio nas leiras do PC, com altura aproximada de $0,35 \mathrm{~m}$, foi realizado com abertura manual de cova com $0,08 \mathrm{~m}$ de profundidade, colocação vertical da base da rama e enterrio também manual. Já no PR,um sulco de $0,08 \mathrm{~m}$ de profundidade por aproximadamente 0,10 $\mathrm{m}$ de largura foi aberto usando-se enxada, com posterior colocação vertical da base da rama. A cobertura de porção da rama com solo também foi realizada empregando-se enxada, com o cuidado de não remover a palha das áreas laterais. A área útil foi constituída pela porção de solo que continha as 18 plantas centrais da leira na linha do meio.

As propriedades de solo avaliadas foram: densidade do solo (Ds), porosidade total (Pt), macroporosidade (Ma), microporosidade (Mi), resistência mecânica do solo à penetração $(\mathrm{RP})$ e umidade gravimétrica do solo (Ug). Houve avaliação dessas propriedades até a profundidade de $0,30 \mathrm{~m}$, pois nessa camada concentram-se as raízes tuberosas de batata-doce.

Para a determinação de $\mathrm{Ds}$, Pt, Ma e Mi, foram coletadas amostras com estrutura indeformada (100 $\mathrm{cm}^{3}$ ) em cada parcela e nove ao acaso na área da mata, aos 120 e 180 dias após o plantio (DAP) de batatadoce, na porção mediana das camadas de 0-0,15 e 0,15$0,30 \mathrm{~m}$. As coletas foram realizadas na leira por linha de plantio. A Ds foi determinada pelo método do anel volumétrico e a Pt por meio da relação existente entre a Ds e a densidade de partículas $(\mathrm{Dp})$ (valor médio de $2,63 \mathrm{~kg} \mathrm{dm}^{-3}$ ). A Mi foi obtida pelo método da mesa de tensão e a Ma pela diferença entre Pt e Mi. Os atributos físicos foram determinados de acordo com Embrapa (1997).

A RP foi determinada empregando-se um penetrômetro de impacto, aos 180 DAP. As medidas foram tomadas na leira/linha de plantio. Em cada parcela experimental, obtiveram-se três medidas de $\mathrm{RP}$, em que foram calculados valores médios. Na área de mata, a RP foi avaliada em 27 pontos inteiramente casualizados para obtenção de nove médias para cada profundidade. Avaliou-se o número de impactos a cada $0,05 \mathrm{~m}$, na camada de $0-0,30 \mathrm{~m}$ de profundidade. Os dados obtidos em número de impactos por dm foram transformados para RP (MPa). Para essa transformação, utilizou-se a equação apresentada por Stolf (1991). Os resultados foram apresentados em valores médios para cada $0,05 \mathrm{~m}$ de profundidade. Também foram retiradas amostras nas camadas de 0-0,10 m, 0,10-0,20 m e 0,20-0,30 m para determinar a Ug, obtida conforme descrito por Embrapa (1997). Foram obtidos três valores por camada em cada parcela para obtenção de valores médios por camada.

Submeteram-se as variáveis $\mathrm{Ds}, \mathrm{Pt}, \mathrm{Ma}$ e Mi à análise de variância e as médias foram comparadas pelo teste de Tukey a $5 \%$. Os dados de RP foram avaliados e analisados, obtendo-se um valor médio em cada profundidade. O erro-padrão da média foi utilizado para proceder à avaliação dos tratamentos em cada profundidade amostrada.

Avaliaram-se o formato das raízes tuberosas de batata-doce nos sistemas de preparo convencional e reduzido, por meio das relações comprimento e diâmetro, a massa fresca e o comprimento dessas raízes. Foram consideradas as raízes com massa fresca individual entre 80 e $1.000 \mathrm{~g}$. Essa parte do trabalho foi realizada em blocos ao acaso, com seis repetições, esquema de parcelas subdivididas, sendo essas constituídas pelos preparos de solo convencional e reduzido e as subparcelas por quatro épocas de colheita: 90, 120, 150 e 180 DAP. As parcelas também foram constituídas por três leiras/linhas; a área útil foi composta pelas plantas centrais da leira/linha do meio, conforme descrito anteriormente.

Os dados obtidos com as relações comprimento/ diâmetro e massa fresca/comprimento foram submetidos à análise de variância e as médias foram ajustadas a equações de regressão polinomial. O critério para a escolha do modelo foi a significância pelo teste $\mathrm{F}$ a $5 \%$ e os maiores valores do coeficiente de determinação $\left(R^{2}\right)$.

\section{RESULTADOS E DISCUSSÃO}

Na variável Ds, houve interação entre formas de preparo do solo e camadas analisadas nas duas épocas 
consideradas. Aos 120 DAP, na camada 0-0,15 m, a Ds no PC foi menor que a densidade encontrada no PR (Quadro 1). Esse resultado já era esperado, pois o revolvimento de solo, promovido por meio do uso de arado de disco, grade niveladora e posterior confecção de leira, provoca intensa pulverização desse no PC, diminuindo a Ds na camada mobilizada. Na camada de $0,15-0,30 \mathrm{~m}$, a Ds existente no PC não apresentou diferença em relação ao PR. Verificou-se também que a Ds na camada mais superficial, nos dois tratamentos, apresentou valor menor que na camada mais profunda, provavelmente pelo fato de essa camada ser menos influenciada pelo preparo do solo e apresentar menor quantidade de matéria orgânica $(\mathrm{PC}=4,79$ e 2,72 g $\mathrm{dm}^{-3}$ de $\mathrm{C}$ e $\mathrm{PR}=6,70$ e $3,93 \mathrm{~g} \mathrm{dm}^{-3} \mathrm{de} \mathrm{C}$, nas camadas 0-0,15 e 0,15-0,30 m, respectivamente).

$\mathrm{Na}$ segunda avaliação, $180 \mathrm{DAP}$, nas duas camadas (0-0,15 e 0,15-0,30 m), o PC apresentou Ds inferior ao $\mathrm{PR}$, em razão de seu revolvimento (Quadro 1). Na comparação entre os preparos de solo, nas duas camadas em PC, verificou-se maior Ds na camada de 0,15-0,30 m, enquanto o PR apresentou densidades semelhantes nas duas camadas.

Assim, no PC, nas duas coletas, a camada mais profunda apresentou maior Ds em relação à camada superficial, enquanto no PR essa diferença ocorreu apenas aos 120 DAP. A diferença entre camadas no PC provavelmente ocorreu em razão da operação de confecção das leiras, onde a camada superficial sofre menor compressão lateral do equipamento (sulcador) que as confecciona. No caso do PR, a semelhança de Ds entre camadas aos 180 DAP pode ser explicada pela própria acomodação da camada superficial do solo no longo do tempo.

A comparação entre Ds entre sistemas de preparo tem como resultado frequente a menor densidade em camadas superficiais em solos convencionalmente preparados em relação a solos não revolvidos (plantio direto - PD), conforme verificado neste estudo e em trabalhos de Bertol et al. (2000), Stone \& Silveira (2001), Secco et al. (2005) e Llanillo et al. (2006). Essa situação deve-se à consolidação natural do solo em razão da ausência de preparo no $\mathrm{PD}$ e da diminuição da densidade promovida pelo revolvimento do solo no PC, que neste trabalho apresenta ainda a mobilização do solo pela operação de confecção de leira. No entanto, em áreas onde o sistema PD encontra-se consolidado, a Ds pode ser inferior nesse sistema em relação ao verificado em áreas sob preparo convencional, como evidenciado por Costa et al. (2003), que constataram que o $\mathrm{PD}$, em prática há 21 anos, proporcionou redução de $9 \%$ na Ds em subsuperfície $(0,10-0,20 \mathrm{~m}$ de profundidade) em relação ao plantio convencional com arado de disco, em um Latossolo Bruno.

Na comparação entre Mata e preparos de solo, verificou-se que aos $120 \mathrm{DAP}$ o PC apresentou Ds inferior à Mata na camada 0-0,15 m, em função da intensa pulverização do solo nessa camada, enquanto o PR proporcionou valor superior, o que se deve, provavelmente, pela maior quantidade de matéria orgânica na camada superficial de Mata, associada à ausência de tráfego de maquinário e animais nessa área (Quadro 1). Já aos 180 DAP, o PC e a Mata apresentaram semelhantes valores de Ds, mas, no PR, a Ds continuou apresentando maiores valores que Mata.

Estudos comparativos entre os sistemas de preparo do solo e áreas não agrícolas (mata ou cerrado nativos) geralmente relatam Ds superior em solos utilizados para agricultura, sejam preparados convencionalmente ou em PD, conforme apresentado por Carneiro et al. (2009), Figueiredo et al. (2009), Ferreira et al. (2010) e Cunha et al. (2011), o que é justificado, segundo esses autores, pelo tráfego de máquinas e equipamentos agrícolas e pelo pisoteio de animais. No entanto, assim como neste trabalho, Araújo et al. (2007) verificaram semelhança entre densidades de solo preparado convencionalmente e área de vegetação nativa.

Quanto à Pt, Ma e Mi, também houve interação significativa entre formas de preparo do solo e camada analisada na primeira coleta. Aos $180 \mathrm{DAP}$, houve interação entre os tratamentos apenas para Pt e Ma.

Quadro 1. Densidade do solo aos 120 e 180 dias após plantio de batata-doce, em Argissolo Vermelho-Amarelo submetido a preparo convencional (PC) e preparo reduzido (PR) e área de mata nativa, em duas profundidades

\begin{tabular}{|c|c|c|c|c|}
\hline \multirow{3}{*}{ Preparo do solo/Mata } & \multicolumn{4}{|c|}{ Densidade do solo } \\
\hline & \multicolumn{2}{|c|}{120 DAP } & \multicolumn{2}{|c|}{180 DAP } \\
\hline & 0-0,15 m & 0,15-0,30 m & 0-0,15 m & 0,15-0,30 m \\
\hline & & 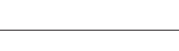 & & \\
\hline $\mathrm{PC}$ & $1,28 \mathrm{Aa}^{*}$ & $1,55 \mathrm{Ab}$ & $1,24 \mathrm{Aa}$ & $1,43 \mathrm{Ab}$ \\
\hline PR & $1,50 \mathrm{Ba}^{*}$ & $1,58 \mathrm{Ab}^{*}$ & $1,57 \mathrm{Ba}^{*}$ & $1,61 \mathrm{Ba}^{*}$ \\
\hline $\mathrm{CV}(\%)$ & 5,80 & 3,79 & & \\
\hline Mata & 1,42 & 1,48 & 1,22 & 1,45 \\
\hline
\end{tabular}

Letras maiúsculas iguais entre os tipos de preparo do solo e na mesma profundidade e letras minúsculas iguais entre as duas profundidades e no mesmo preparo do solo não diferem entre si pelo teste de Tukey $(\mathrm{p}<0,05)$. Médias seguidas de * diferem significativamente da Mata pelo teste de Dunnett a 5\%. 
Na primeira avaliação, aos 120 DAP, na camada de $0-0,15 \mathrm{~m}$, a Pt e a Ma foram maiores no PC que no PR, ocorrendo o contrário em Mi (Quadro 2). O maior valor de Ma verificado no sistema com revolvimento deve-se à persistência dos efeitos da mobilização do solo, que resultaram em quebra dos agregados e desenvolvimento de poros, notadamente macroporos, como comprovam os resultados obtidos por Bertol et al. (2004). Na camada de 0,15-0,30 m, Pt, Ma e Mi não diferiram entre os tratamentos, em razão, provavelmente, a um processo natural de acomodação de partículas em subsuperfície (Calonego et al., 2012), em especial no sistema onde houve revolvimento do solo, tornando-o semelhante ao PR.

Com relação às características avaliadas nas duas camadas, no PC, a Pt e Ma foram menores na camada subsuperficial. Essa diferença deve-se ao ajuste de partículas na camada subsuperficial devido ao entupimento dos poros pelas partículas mais finas e dos ciclos de umedecimento e secagem do solo (Oliveira et al., 1996), com consequente aumento no valor de Mi. No PR, não houve diferença nas variáveis em relação às camadas avaliadas.

Quanto a semelhanças entre Mata e sistemas de preparo, apenas houve diferença na comparação entre Pt de PC e Mi de PR, ou seja, o PC resultou em maior porosidade do solo que Mata, enquanto $\mathrm{PR}$, maior valor de Mi.

Aos 180 DAP, na camada de 0-0,15 m, Pt e Ma no PC mantiveram-se superiores ao PR (Quadro 3). Na

Quadro 2. Porosidade total (Pt), macroporosidade (Ma) e microporosidade (Mi) aos 120 dias após plantio de batata-doce, em Argissolo VermelhoAmarelo submetido a preparo convencional (PC) e preparo reduzido (PR) e área de mata nativa, em duas profundidades

\begin{tabular}{cccc}
\hline Preparo do solo/Mata & $\mathbf{P t}$ & $\mathbf{M a}$ & $\mathbf{M i}$ \\
\cline { 2 - 4 } & \multicolumn{3}{c}{$\mathrm{cm}^{3} \mathrm{~cm}^{-3}$} \\
\cline { 2 - 4 } PC & $0,0,15 \mathrm{~m} \mathrm{Aa}^{*}$ & $0,33 \mathrm{Aa}$ & $0,16 \mathrm{Bb}$ \\
PR & $0,43 \mathrm{Ba}$ & $0,22 \mathrm{Ba}$ & $0,21 \mathrm{Aa}^{*}$ \\
CV $(\%)$ & 8,54 & 19,92 & 7,96 \\
Mata & 0,46 & 0,29 & 0,17 \\
& & $0,15-0,30 \mathrm{~m}$ & \\
PC & $0,41 \mathrm{Ab}$ & $0,20 \mathrm{Ab}$ & $0,21 \mathrm{Aa}$ \\
PR & $0,41 \mathrm{Aa}$ & $0,20 \mathrm{Aa}$ & $0,21 \mathrm{Aa}$ \\
CV (\%) & 8,54 & 19,92 & 7,96 \\
Mata & 0,44 & 0,26 & 0,18 \\
\hline
\end{tabular}

Letras maiúsculas iguais entre os tipos de preparo do solo na coluna e na mesma profundidade e letras minúsculas iguais entre as duas profundidades e no mesmo preparo do solo não diferem entre si pelo teste de Tukey $(p<0,05)$. Médias seguidas de * diferem significativamente da Mata pelo teste de Dunnett a $5 \%$ camada mais profunda, 0,15-0,30 m, Pt e Ma apresentaram valores superior no $\mathrm{PC}$ em relação ao $\mathrm{PR}$, diferentemente do ocorrido aos $120 \mathrm{DAP}$, o que, provavelmente, deve-se ao efeito do incremento do volume das raízes tuberosas, que acabam por aumentar a densidade do solo na linha de plantio no $\mathrm{PR}$, com consequente diminuição da Pt. Tal fato não ocorre no PC, pois, com o incremento do volume das raízes tuberosas, o solo das leiras pode deslocar-se lateralmente, o que é visualizado por meio de rachaduras nas leiras. Quanto à Mi, PR apresentou maior valor, mas não houve diferença entre profundidades.

Nessa época de coleta, também houve pouca diferença das características avaliadas entre sistemas de preparo e Mata (Quadro 3). Apenas PR resultou em menores valores de Pt que mata, nas duas camadas, diferentemente do relatado por Argenton et al. (2005), em que a área de mata apresentou maior macroporosidade que áreas sob preparos reduzido e convencional.

Ressalta-se que nas duas épocas de coleta, as semelhanças ou diferenças de Pt obtidas entre as duas formas de preparos de solo também ocorreram na Ds.

Comparando-se as duas épocas de coleta, verificouse que após 60 dias da primeira coleta, ou seja, aos 180 DAP, a Pt de Mata que, aos 120 DAP, apresentava valor inferior a PC e semelhante a PR, tornou-se semelhante entre Mata e PC e superior a PR (Quadros 2 e 3). Tal fato deve-se à reorganização do solo em razão do tempo em áreas cultivadas. Em trabalho de Silva et al. (2008) ocorreu algo semelhante: na camada 0-0,10 m de um Argissolo Vermelho textura arenosa, o PC do solo resultou em maiores valores de Pt e Ma e semelhante valor de Mi em relação ao PD, e 15 meses após o solo não apresentou diferenças nesses atributos nos dois sistemas.

Da mesma forma que a Ds, os atributos relacionados à porosidade do solo respondem de maneira diferenciada, conforme o tipo de solo, sua utilização e seu histórico de cultivo. Silva et al. (2006) também verificaram maior quantidade de macroporos em camada superficial de Argissolo Vermelho preparado convencionalmente em relação ao $\mathrm{PD}$ e campo nativo, o que, segundo Cruz et al. (2003), devese à desestruturação do solo e, consequentemente, maior quantidade de poros obtidos com o PC do solo. Contudo, Silva et al. (2006), em Argissolo Vermelho textura média, verificaram semelhanças na porosidade total de PC, PD e campo nativo em experimento com 17 anos. Assis \& Lança (2005) encontraram semelhantes valores nos atributos macro e microporosidades entre PC, PD com até cinco anos e mata nativa. Ressalta-se que a prática do $\mathrm{PD}$ em longo período de tempo favorece os atributos físicos do solo, tornando-os mais adequados ao desenvolvimento vegetal que o PC, conforme verificado por Tavares Filho et al. (2001), em Latossolo Vermelho argiloso, com PD sendo realizado há mais de 20 anos. 
Na comparação entre preparo do solo e área não cultivada (vegetação nativa), é verificado que os valores de Pt e Ma foram semelhantes em PC e Mata, ocorrendo inclusive maiores valores em PC, o que, provavelmente, foi em razão da intensa mobilização do solo e da incorporação da palha de milho e braquiária, que favorecem a manutenção dos poros após o revolvimento do solo. Souza et al. (2005) verificaram que a mobilização do solo juntamente com a incorporação de palha promove redução de Ds e Mi e aumento nos valores de Pt e Ma. Cunha et al. (2011) e Figueiredo et al. (2009) observaram maiores valores de Pt e Ma em solo sob vegetação nativa que em áreas cultivadas e justificaram tal fato como ausência de trânsito de máquinas e equipamentos ou animais em área de mata.

Com relação à $R P$, salienta-se que essa propriedade está relacionada à densidade, umidade encontrada $\mathrm{e}$ textura do solo (Rosolem et al., 1999). Os resultados de RP obtidos aos 180 DAP são apresentados na figura 1a e as respectivas $\mathrm{Ug}$, na figura $1 b$.

No PC, o penetrômetro não registrou resistência do solo à penetração até $0,10 \mathrm{~m}$, enquanto na área de Mata a resistência encontrada foi de $0,80 \mathrm{MPa}$ e no PR, de 1,14 MPa. Nessa camada, no PC, o solo encontrava-se menos úmido que em Mata e PR, mas tal fato não foi suficiente para impor resistência ao penetrômetro. Até a profundidade de $0,25 \mathrm{~m}, \mathrm{PC}$ resultou em menor RP que Mata e PR. Entretanto, nessa profundidade, $0,25 \mathrm{~m}$, a RP em $\mathrm{PC}$ foi

Quadro 3. Porosidade total (Pt), macroporosidade (Ma) e microporosidade (Mi) aos 180 dias após plantio de batata-doce, em Argissolo VermelhoAmarelo submetido a preparo convencional (PC) e preparo reduzido (PR) e área de mata nativa, em duas profundidades

\begin{tabular}{ccccc}
\hline $\begin{array}{c}\text { Preparo do } \\
\text { solo/Mata }\end{array}$ & Pt & Ma & Pt & Ma \\
\cline { 2 - 5 } & \multicolumn{5}{c}{$0-0,15 \mathrm{~m} \mathrm{~cm}^{3} \mathrm{~cm}^{-3}$} \\
\cline { 2 - 5 } PC & $0,53 \mathrm{Aa}$ & $0,36 \mathrm{Aa}$ & $0,45 \mathrm{Ab}$ & $0,26 \mathrm{Ab}$ \\
PR & $0,40 \mathrm{Ba}^{*}$ & $0,21 \mathrm{Ba}$ & $0,39 \mathrm{Ba}^{*}$ & $0,20 \mathrm{Ba}$ \\
CV \% & 4,47 & 12,29 & 4,57 & 12,29 \\
Mata & 0,53 & 0,33 & 0,45 & 0,16 \\
& \multicolumn{5}{c}{$\mathrm{Mi}, \mathrm{cm}^{3} \mathrm{~cm}^{-3}$} \\
PC & $0,17 \mathrm{~B}$ & Profundidade \\
PR & $0,19 \mathrm{~A}$ & $0-0,15 \mathrm{~m}$ & $0,18 \mathrm{~A}$ \\
CV(\%) & 9,60 & $0,15-0,30 \mathrm{~m}$ & $0,19 \mathrm{~B}$ \\
Mata & 0,18 & $\mathrm{CV}(\%)$ & 9,60 \\
\hline
\end{tabular}

Letras maiúsculas iguais entre os tipos de preparo do solo na coluna e na mesma profundidade e letras minúsculas iguais entre as duas profundidades e no mesmo preparo do solo não diferem entre si pelo teste de Tukey $(\mathrm{p}<0,05)$. Médias seguidas de * diferem significativamente da Mata pelo teste de Dunnett a $5 \%$ semelhante à encontrada na área de Mata, embora ambas fossem inferiores à RP em PR. Na profundidade de $0,30 \mathrm{~m}$, os valores de RP dos três tratamentos foram semelhantes $(\mathrm{PC}=2,70 \mathrm{MPa} ; \mathrm{Mata}=2,92 \mathrm{MPa} ; \mathrm{PR}$ $=3,10 \mathrm{MPa})$ e apresentaram-se maiores que nas demais profundidades, embora nessa profundidade a Ug tenha atingido o máximo valor observado em $\mathrm{PC}$ e $\mathrm{PR}$. A maior RP no $\mathrm{PR}$ em relação à Mata e ao $\mathrm{PC}$ está relacionada a maior $\mathrm{Ds}$ e menores $\mathrm{Pt}$ e $\mathrm{Ma}$ encontrados na época de avaliação, embora semelhantes valores de Ds entre tratamentos não resultem obrigatoriamente em semelhantes valores de $R P$, visto que outros fatores também interferem (umidade e textura do solo), como verificado entre PC e Mata aos 180 DAP (iguais Ds e Ma, mas diferentes RP) e em trabalho de Prado et al. (2002). Ralisch et al. (2008) ressaltaram que os primeiros anos de adoção do sistema de PD são acompanhados de maior RP nas camadas superficiais do solo.

A semelhança de RP entre PR e Mata na camada $0,0-0,10 \mathrm{~m}$ pode ter sido em razão da maior umidade

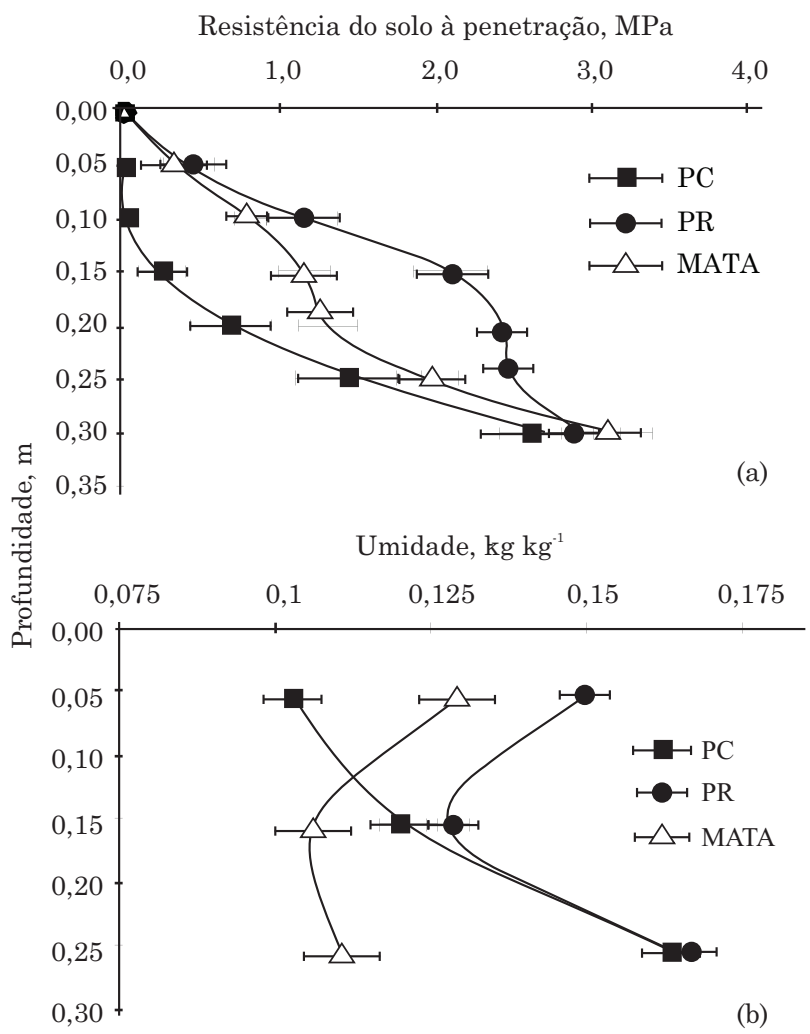

Figura 1. Resistência mecânica do solo à penetração (a) e umidade gravimétrica (b) em Argissolo Vermelho-Amarelo submetido a preparo convencional (PC), preparo reduzido (PR) e área de mata nativa, em diferentes profundidades, aos 180 dias após plantio de batata-doce. *As barras indicam os valores de erro-padrão da média e, a sobreposição dessas, a ausência de diferenças entre as médias dos tratamentos. 
encontrada nessa camada no PR. No entanto, áreas com vegetação natural geralmente apresentam menores valores de RP que solos com uso agrícola, conforme observado por Argenton et al. (2005) e Tavares Filho et al. (2010).

Segundo Tavares Filho et al. (2001), houve maior $\mathrm{RP}$ no $\mathrm{PD}$ até a profundidade de $0,15 \mathrm{~m}$ em relação ao $\mathrm{PC}$ e, na camada $0,15-0,35 \mathrm{~m}$, os valores de $\mathrm{RP}$ entre os dois sistemas não diferiram, enquanto em maior profundidade a RP foi menor no PD. Ressalta-se que, em tal trabalho, o sistema PD era adotado por período superior a 20 anos, ou seja, os benefícios do PD já se estendiam além da camada superficial.

Quanto à umidade do solo, pode-se observar, pela figura $1 b$, que na camada de solo de $0-0,10 \mathrm{~m}$, a Ug no PC foi menor que na Mata e no PR; nesse último, a Ug foi superior também à área de Mata. No entanto, nas camadas de 0,10-0,20 e 0,20-0,30 m, a Ug das camadas do PC e do PD foram semelhantes, mas maiores que na área de Mata. O menor valor de umidade em Mata nessa camada pode ser por causada maior perda de água do solo por meio da transpiração das árvores e arbustos, visto que, segundo Bellot et al. (1999), vegetações com grande quantidade de biomassa consomem maior quantidade de água do solo que vegetações de menor porte.

A maior Ug na camada superficial encontrada no PR foi favorecida pela presença de palha, o que, segundo Martorano et al. (2009), os resíduos mantidos na superfície implicam em temperatura máxima e amplitude térmica menores, favorecendo a manutenção da água no solo (Fabrizzi et al., 2005; Fasinmirin \& Reichert, 2011), principalmente pela menor perda de água por evaporação (Agbede, 2010). Tavares Filho et al. (2001) e Mateus et al. (2007) também destacaram a importância da presença de restos vegetais sobre a superfície do solo em PD na manutenção de água no solo.

O sistema de preparo do solo também influenciou o formato das raízes tuberosas de batata-doce. Houve interação significativa entre sistema de preparo e época de colheita. No PC, a resposta da relação comprimento/diâmetro de raízes tuberosas foi linear com decréscimo da primeira (90 DAP) à última colheita (180 DAP). Assim, houve aumento do diâmetro de raízes tuberosas em relação ao comprimento por causa do tempo, ou seja, o diâmetro das raízes tuberosas foi constantemente ampliado em razão da maior permanência das plantas no campo (Figura 2).

No PR, a relação comprimento/diâmetro de raízes tuberosas não apresentou diferença significativa entre as datas de colheita, permanecendo, em média, em $2,45 \mathrm{~cm} \mathrm{~cm}^{-1}$, ou seja, o comprimento manteve-se maior que o dobro do diâmetro. No entanto, como o valor da característica foi inferior ao ocorrido no PC, constatou-se que o formato das raízes tuberosas no sistema sem preparo foi menos alongado que no PC. Tal fato deve-se ao maior valor de $\mathrm{RP}$ das raízes encontrada no PR na camada $0-0,25 \mathrm{~m}$, propriedade que, segundo Barley et al. (1965), afeta diretamente o alongamento das raízes.

Tais informações indicaram que, em PR, o acúmulo de matéria seca nas raízes tuberosas pode ter ocorrido de maneira mais lenta que em PC, em razão de menor Pt e maiores valores de densidade e RP no PR do solo, o que limita a exploração do solo em volume pelas raízes tuberosas e absorventes. De acordo com Agbede (2006), em pesquisa com inhame, a maior Ds pode causar resistência mecânica à raiz e ao crescimento dos órgãos de reserva subterrâneos, inclusive comprimento, prejudicando a absorção de nutrientes e de água pela planta. Em trabalho com batata-doce, Agbede \& Adekiya (2009) verificaram que no PD as plantas apresentaram folhas e raízes tuberosas com menores teores de $\mathrm{N}, \mathrm{P}, \mathrm{K}, \mathrm{Ca}$ e $\mathrm{Mg}$, em relação ao preparo convencional do solo.

$\mathrm{Na}$ relação entre massa fresca individual/ comprimento de raízes tuberosas, também houve interação entre sistema de plantio e época de colheita. Em ambos os preparos do solo, a resposta estimada foi linear crescente com a maior permanência das plantas no campo, o que era esperado, pois há incremento de substâncias reservas armazenadas em raízes tuberosas de batata-doce no longo do tempo (Figura 3). No entanto, PR proporcionou maior massa fresca individual de raízes tuberosas por unidade de comprimento de raízes que $\mathrm{PC}$, o que confirma o formato menos alongado demonstrado pela relação entre comprimento e diâmetro. Dessa forma, as raízes mais arredondadas produzidas em PR conferem ao produto menor valor comercial, pois o mercado consumidor prefere formato alongado.

Como já descrito, o $\mathrm{PR}$ proporciona maiores Ds e $\mathrm{RP}$ de raízes. As raízes tuberosas de batata-doce são sensíveis a essas diferenças e respondem com alteração em seu formato. O PC favorece o formato mais

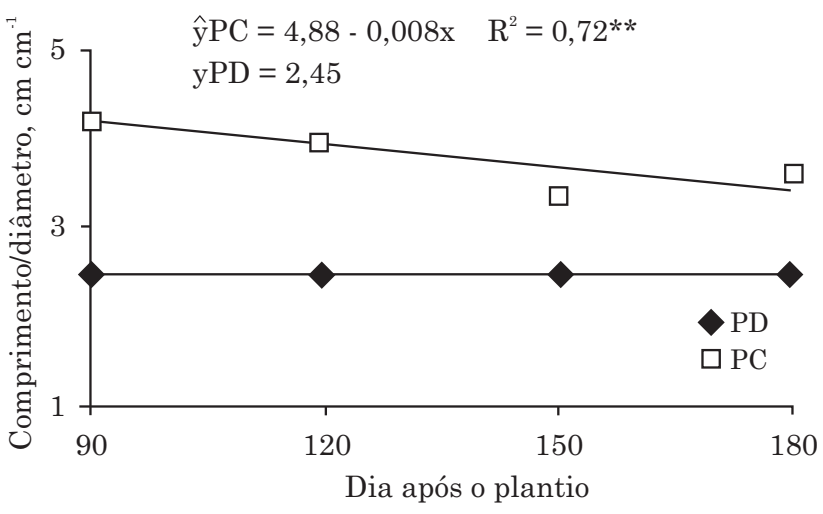

Figura 2. Comprimento/diâmetro de raízes tuberosas de plantas de batata-doce cultivadas em Argissolo Vermelho-Amarelo submetido a preparo convencional (PC) e preparo reduzido (PR), em razão de dias após plantio. **Significativo a $1 \%$ pelo teste $\mathbf{F}$. 


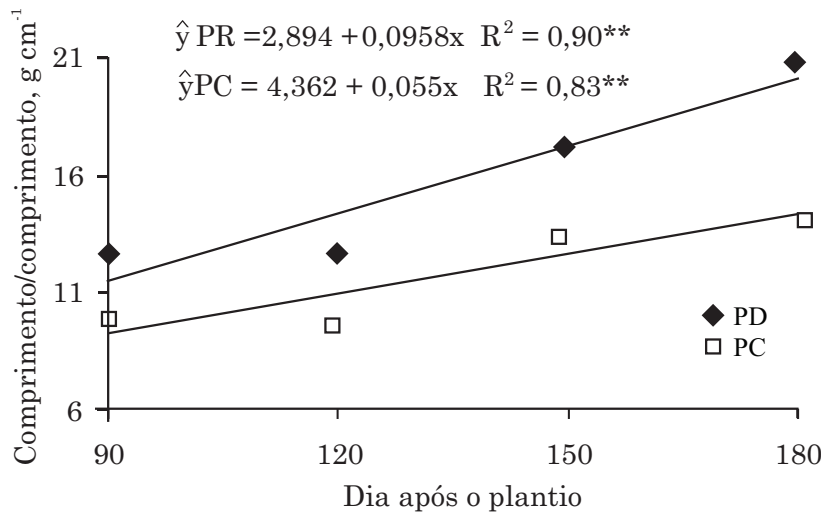

alongado, pois a menor $\mathrm{RP}$ permite que as raízes cresçam mais em comprimento, favorecendo a distribuição das substâncias de reserva ao longo de maior comprimento, enquanto o PR, por apresentar condições de maior RP, limita o crescimento dessas em comprimento, o que as faz armazenar suas substâncias de reserva em menor espaço longitudinal. De acordo com Agbede (2006), tubérculos de inhame apresentaram redução em seu comprimento com solo com maior densidade.

\section{CONCLUSÕES}

1. O preparo convencional com confecção de leira, na camada superficial, $0,0-0,15 \mathrm{~m}$, proporciona menores valores de densidade e microporosidade e maiores valores de porosidade total e macroporosidade, em comparação com o preparo reduzido do solo.

2. O preparo reduzido confere maior resistência mecânica à penetração no solo na camada $0-0,25 \mathrm{~m}$ que o preparo convencional, tornando as raízes tuberosas de batata-doce menos alongadas.

\section{AGRADECIMENTO}

À CAPES, pela concessão de bolsa de doutoramento à primeira autora.

\section{LITERATURA CITADA}

AGBEDE, T.M. Effect of tillage on soil properties and yam yield on an Alfisol in southwestern Nigeria. Soil Tillage Res., 86:1-8, 2006.

AGBEDE, T.M. Tillage and fertilizer effects on some soil properties, leaf nutrient concentrations, growth and sweet potato yield on an Alfisol in southwestern Nigeria. Soil Tillage Res., 101:25-35, 2010.
AGBEDE, T.M. \& ADEKIYA, A.O. Tillage effects on soil properties and performance of sweet potato on an Alfisol in Southwestern Nigeria. Eur. J. Sustain. Agric., 3:561$568,2009$.

ARAÚJO, R.; GOEDERT, W.J. \& LACERDA, M.P.C. Qualidade de um solo sob diferentes usos e sob Cerrado nativo. R. Bras. Ci. Solo, 31:1099-1108, 2007.

ARGENTON, J.; ALBUQUERQUE, J.A.; BAYER, C. \& WILDNER, L.P. Comportamento de atributos relacionados com a forma da estrutura de Latossolo Vermelho sob sistemas de preparo e plantas de cobertura. R. Bras. Ci. Solo, 29:425-435, 2005.

ASSIS, R.L. \& LANÇAS, K.P. Avaliação dos atributos físicos de um Nitossolo Vermelho distroférrico sob sistema plantio direto, preparo convencional e mata nativa. R. Bras. Ci. Solo, 29:515-522, 2005.

BARLEY, K.P.; FARRELL, D.A. \& GREACEN, E.L. The influence of soil strength on the penetration of a loam by plant roots. Aust. J. Soil Res., 3:69-79, 1965.

BARRERA, P. Batata-doce: uma das doze mais importantes culturas do mundo. São Paulo, Ícone, 1986. 91p.

BELLOT, J.; SANCHEZ, J.R.; CHIRINO, E.; HERNANDEZ, N.; ABDELLI, F. \& MARTINEZ, J.M. Effect of different vegetation type cover on the soil water balance in semiarid areas of South Eastern Spain. Phys. Chem. Earth, 24:353-357, 1999.

BERTOL, I.; ALBUQUERQUE, J.S.; LEITE, D.; AMARAL, A \& ZOLDAN JUNIOR, W.A. Propriedades físicas do solo sob preparo convencional e semeadura direta em rotação e sucessão de culturas comparadas às do campo nativo. R. Bras. Ci. Solo, 28:155-163, 2004.

BERTOL, I.; SCHICK, J.; MASSARIOL, J.M.; REIS, E.F. \& DILY, L. Propriedades físicas de um Cambissolo Húmico álico afetadas pelo manejo do solo. Ci. Rural, 30:91-95, 2000 .

CALONEGO, J.C.; SANTOS, C.H.; TIRITAN, C.S. \& CUNHA JUNIOR, J.R. Estoques de carbono e propriedades físicas de solos submetidos a diferentes sistemas de manejo. R. Caatinga, 25:128-135, 2012.

ARNEIRO, M.A.C.; SOUZA, E.D.; REIS, E.F.; PEREIRA, H.S. \& AZEVEDO, W.R. Atributos físicos, químicos e biológicos de solo de cerrado sob diferentes sistemas de uso e manejo. R. Bras. Ci. Solo, 33:147-157, 2009.

CARTER, M.R. \& SANDERSON, J.B. Influence of conservation tillage and rotation length on potato productivity, tuber disease and soil quality parameters on a fine sandy loam in eastern Canada. Soil Tillage Res., 63:1-13, 2001.

COSTA, F.S.; ALBUQUERQUE, J.A.; BAYER, C.; FONTOURA, S.M.V. \& WOBETO, C. Propriedades físicas de um Latossolo Bruno afetadas pelos sistemas plantio direto e preparo convencional. R. Bras. Ci. Solo, 27:527$535,2003$.

CRUZ, A.C.R.; GOEDERT, W.J. \& SOUSA, D.M.G. Atributos físicos e carbono orgânico de um Argissolo Vermelho sob sistemas de manejo. Pesq. Agropec. Bras., 27:1105-1112, 2003. 
CUNHA, E.Q.; STONE, L.F.; MOREIRA, J.A.A.; FERREIRA, E.P.B.; DIDONET, A.D. \& LEANDRO, W.M. Sistemas de preparo do solo e culturas de cobertura na produção orgânica de feijão e milho. I - Atributos físicos do solo. R. Bras. Ci. Solo, 35:589-602, 2011.

EMPRESA BRASILEIRA DE PESQUISA AGROPECUÁRIA EMBRAPA. Centro Nacional de Pesquisa de Solos. Sistema brasileiro de classificação de solos. 2.ed. Rio de Janeiro, 2006. 306p.

EMPRESA BRASILEIRA DE PESQUISA AGROPECUÁRIA EMBRAPA. Centro Nacional de Pesquisa de Solo. Manual de métodos de análise de solo. 2.ed. Rio de Janeiro, 1997. $212 \mathrm{p}$.

FABRIZZI, K.P.; GARCIA, F.O.; COSTA, J.L. \& PICONE, L.I. Soil water dynamics, physical properties and corn and wheat responses to minimum and no-tillage systems in the southern Pampas of Argentina. Soil Tillage Res., 81:57-69, 2005.

FASINMIRIN, J.T. \& REICHERT, J.M. Conservation tillage for cassava (Manihot esculenta Crantz) production in the tropics. Soil Tillage Res.,113:1-10, 2011.

FERREIRA, R.R.M.; TAVARES FILHO, J. \& FERREIRA, V.M. Efeitos de sistemas de manejo de pastagens nas propriedades físicas do solo. Semina: Ci. Agron.,31:913932, 2010.

FIGUEIREDO, C.C.; SANTOS, G.G.; PEREIRA, S.; NASCIMENTO, J.L. \& ALVES JUNIOR, J. Propriedades físico-hídricas em Latossolo do Cerrado sob diferentes sistemas de manejo. R. Bras. Eng. Agríc. Amb., 13:146$151,2009$.

FONTES, P.C.R.; NUNES, J.C.S.; FERNANDES, H.C. \& ARAÚJO, E.F. Características físicas do solo e produtividade da batata dependendo de sistemas de preparo do solo. Hortic. Bras., 25:355-359, 2007.

LLANILLO, R.F.; RICHART, A.; TAVARES FILHO, J.; GUIMARÃES, M.F. \& FERREIRA, R.R.M. Evolução de propriedades físicas do solo em função dos sistemas de manejo em culturas anuais. Semina: Ci. Agron., 27:205$220,2006$.

MARTORANO, L.G.; BERGAMASCHI, H.; DALMAGO, G.A.; FARIA, R.T.; MIELNICZUK, J. \& COMIRAN, F. Indicadores da condição hídrica do solo com soja em plantio direto e preparo convencional. R. Bras. Eng. Agríc. Amb., 13:397-405, 2009.

MATEUS, G.P.; CRUSCIOL, C.A.C. \& BORGHI, E. Efeito da palhada do sorgo de guiné "gigante" na nutrição foliar e produtividade da soja em plantio direto. Acta Sci. Agron., 29:497-502, 2007.

OLIVEIRA, T.S.; COSTA, L.M.; FIGUEIREDO, M.S. \& REGAZZI, A.J. Efeitos dos ciclos de umedecimento e secagem sobre a estabilidadede agregados em água de quatro Latossolos brasileiros. R. Bras. Ci. Solo, 20:509$515,1996$.

OTSUBO, A.A.; MERCANTE, F.M.; SILVA, R.F. \& BORGES, C.D. Sistemas de preparo do solo, plantas de cobertura e produtividade da cultura da mandioca. Pesq. Agropec. Bras., 43:327-332, 2008.
PRADO, R.M.; ROQUE, C.G. \& SOUZA, Z.M. Sistemas de preparo e resistência à penetração e densidade de um Latossolo Vermelho eutrófico em cultivo intensivo e pousio. Pesq. Agropec. Bras., 37:1795-1801, 2002.

RALISCH, R.; MIRANDA, T.M.; OKUMURA, R.S.; BARBOSA, G.M.C.; GUIMARÃES, M.F.; SCOPEL, E. \& BALBINO, L.C. Resistência à penetração de um Latossolo VermelhoAmarelo do Cerrado sob diferentes sistemas de manejo. R. Bras. Eng. Agríc. Amb., 12:381-384, 2008.

ROSOLEM, C.A.; FERNANDEZ, E.M.; ANDREOTTI, M. \& CRUSCIOL, C.A.C. Crescimento radicular de plântulas de milho afetado pela resistência do solo à penetração. Pesq. Agropec. Bras., 34:821-828, 1999.

SECCO, D.; ROS, C.O.; SECCO, J.K. \& FIORIN, J.E. Atributos físicos e produtividade de culturas em um Latossolo Vermelho argiloso sob diferentes sistemas de manejo. R. Bras. Ci. Solo, 29:407-414, 2005.

SILVA, R.F.; BORGES, C.D.; GARIB, D.M. \& MERCANTE, F.M. Atributos físicos e teor de matéria orgânica na camada superficial de um Argissolo Vermelho cultivado com mandioca sob diferentes manejos. R. Bras. Ci. Solo, 32:2435-2441, 2008.

SILVA, M.A.S.; MAFRA, A.L.; ALBUQUERQUE, J.A.; ROSA, J.D.; BAYER, C. \& MIELNICZUK, J. Propriedades físicas e teor de carbono orgânico de um Argissolo Vermelho sob distintos sistemas de uso e manejo. R. Bras. Ci. Solo, 30:329-337, 2006.

SOUZA, Z.M.; PRADO, R.M.; PAIXÃO, A.C.S. \& CESARIN, L.G. Sistemas de colheita e manejo da palhada de canade-açúcar. Pesq. Agropec. Bras., 40:271-278, 2005.

STOLF, R. Teoria e teste experimental de fórmulas de transformação dos dados de penetrômetro de impacto em resistência do solo. R. Bras. Ci. Solo, 15:229-235, 1991.

STONE, L.F. \& SILVEIRA, P.M. Efeitos do sistema de preparo e da rotação de culturas na porosidade e densidade do solo. R. Bras. Ci. Solo, 25:395-401, 2001.

TAVARES FILHO, J.; BARBOSA, G.M.C.; GUIMARÃES, M.F. \& FONSECA, I.C.B. Resistência do solo à penetração e desenvolvimento do sistema radicular do milho (Zea mays) sob diferentes sistemas de manejo em um Latossolo Roxo. R. Bras. Ci. Solo, 25:725-730, 2001.

TAVARES FILHO, J.; BARBOSA, G.M.C. \& RIBON, A.A. Physical properties of dystrophic Red Latosol (Oxisol) under different agricultural uses. R. Bras. Ci. Solo, 34:925933, 2010.

TORMENA, C.A.; BARBOSA, M.C.; COSTA, A.C.S. \& GONÇALVEZ, A.C.A. Densidade, porosidade e resistência à penetração em Latossolo cultivado sob diferentes sistemas de preparo do solo. Sci. Agríc., 59:795-801, 2002.

VIEIRA, M.L. \& KLEIN, V.A. Propriedades físico-hídricas de um Latossolo Vermelho submetido a diferentes sistemas de manejo. R. Bras. Ci. Solo, 31:1271-1280, 2007.

ZERO, V.M. \& LIMA, S.L. Manejo e produtividade da cultura da batata - doce (Ipomoea batatas) no município de Presidente Prudente - SP. Energ. Agric., 20:94-117, 2005. 